\title{
Role of Microperimetry in Observation and Treatment in Patients with Macular Holes
}

\section{AS Zotov, AS Balalin*, SV Balalin, AM Marukhnenko, TG Efremova, SM Purshak and IA Melikhova}

S. Fyodorov Eye Microsurgery Federal State Institution, Volgograd Branch, Russia

*Corresponding Author: AS Balalin, S. Fyodorov Eye Microsurgery Federal State Institution, Volgograd Branch, Russia.
Received: June 11, 2021

Published: June 23, 2021

(C) All rights are reserved by AS Balalin., et al.

\section{Abstract}

Purpose: To assess the role of microperimetry in follow-up and treatment of patients with macular holes.

Materials and Methods: Retrospective study of the minimally invasive vitrectomy results using 25G or 27G technologies in 59 patients (59 eyes) with idiopathic macular holes (IMH) was performed. The examination included the determination of the best corrected visual acuity (BCVA), tonometry, perimetry, ultrasound biometry, optical coherence tomography, fundus photography, microperimetry.

Results: After surgical treatment all patients showed a significant improvement in BCVA and retinal photosensitivity (p < 0.05 ). A formula was derived for the dependence of BCVA after treatment on the initial retinal photosensitivity and the maximal IMH size, which can be applied to predict the results of surgical treatment.

Conclusion: Microperimetry is a modern non-invasive examination method that allows with a higher density and resolution to localize central defects of the visual field and to carry out thorough monitoring before and after surgical treatment. The study of the retinal photosensitivity in the macular region and the maximal IMH size before treatment allow to predict BCVA in the postoperative period.

Keywords: Idiopathic Macular Holes; Microperimetry; Minimally Invasive Vitrectomy; Optical Coherence Tomography

\section{Relevance}

Idiopathic macular hole (IMH) is an acquired disease that leads to decreased central vision, metamorphopsias and central scotoma. The prevalence of IMH is approximately 3.3 per 10,000 population, but the rate increases 10 times in people over the age of 65 [1].

J.D. Gass classification of macular holes was used in the study [1]:

- Stage 1a: Detachment of the foveola. Formation of a macular cyst. Tangential distension of the vitreous body leads to elevation of the foveola, accompanied by increased yellow pigmentation due to accumulation of lutein.

- Stage 1b: It is characterised by elevation of the foveolar retina to the level of the perifoveolar zone, the lipofuscincolored spot changes shape to a yellow ring. The continuous stretching of the foveola leads to a detachment of the deeper retinal layers in the apical zone.

- $\quad$ Stage 2: Macular hole is defined by a full thickness break at this stage, which is less than $400 \mu \mathrm{m}$ in diameter. The full-thickness defect may have eccentric position and at this stage a pseudomembrane may form due to the thickening of 
the vitreous body and its glial proliferation, which however does not close the retinal tissue defect.

- $\quad$ Stage 3: It is characterised by the macular hole size greater than $400 \mu \mathrm{m}$ in diameter with partial vitreomacular traction.

- $\quad$ Stage 4: It is characterised by a macular hole with complete posterior vitreous detachment. However, even with the obvious vitreous detachment, the cortical vitreous traction may remain increasing further the macular hole size.

According to the theory developed by J.D. Gass, the leading role in the pathogenesis of IMH is attributed to vitreoretinal traction.

The surgical treatment is the only treatment method for patients with IMH, in particular minimally invasive three-port vitrectomy $25 \mathrm{G}$ and $27 \mathrm{G}$ with membrane peeling, aimed at correcting the anatomical defect, which in the long term determines the improvement of visual functions [2]. According to numerous studies, microperimetry is the most reliable diagnostic method for determining the functional parameters of the retina. It makes possible to estimate the threshold of the retinal photosensitivity in a specific area of the macula or paramacular zones with the subsequent transfer of these data to the fundus image [3-5]. Microperimetry is based on laser scanning ophthalmoscope technology and retinal tracking, which allow to observe the retina in real time during the functional examination and project a certain light stimulus to a selected point [6-13].

\section{Purpose of the Study}

To assess the role of microperimetry in follow-up and treatment of patients with macular holes.

\section{Materials and Methods}

Retrospective study of 25-27G vitrectomy results in 59 patients (59 eyes) aged 52 to 80 years with idiopathic macular holes (IMH) was carried out. The clinical group included 24 women and 35 men.

\section{Inclusion criteria:}

- $\quad$ Lamellar and full-thickness macular hole at $2^{\text {nd }}, 3^{\text {rd }}$ and $4^{\text {th }}$ stage;

- $\quad$ Best corrected visual acuity (BCVA) less than 0.5.
- Presence of concomitant ocular fundus pathology (retinal detachment, proliferative diabetic retinopathy, optic nerve atrophy);

- Presence of corneal scars or opacities;

- Intraocular tumor.

All patients underwent extended ophthalmologic examination before and after treatment, including determination of BCVA (Phoropter 16625B, Reichert/Leica, USA), tonometry (NT-530, NIDEK CO. LTD., Japan), perimetry ("Perigraf Perikom", SPETSMEDPRIBOR, Russia), ultrasound biometry (A/B AVISO, Quantel Medical Aviso, France), optical coherence tomography (RS-3000 Advance2/RS-3000 Lite2, NIDEK CO. LTD., Japan), photo-registration of eye fundus (CX-1, Canon Inc., USA), fundus microperimetry (MAIA, CenterVue, Italy).

Values of retinal photosensitivity according to fundus microperimetry on MAIA microperimeter: normal values: $25 \mathrm{~dB}$ to $36 \mathrm{~dB}$; borderline conditions: $22 \mathrm{~dB}$ to $24 \mathrm{~dB}$; pathology: $21 \mathrm{~dB}$ and below.

Fixation stability is determined on microperimeter by fixation stability index, which is based on the following parameters: if more than $75 \%$ of the fixation points are within a circle of 2 degrees diameter located in the "center of gravity" of all fixation points, the fixation is classified as stable; if less than $75 \%$ of the fixation points are within a circle of 2 degrees diameter, but more than $75 \%$ of the fixation points are within a circle of 4 degrees diameter, the fixation is classified as relatively unstable; if less than $75 \%$ of the fixation points are within a circle of 4 degrees diameter, the fixation is classified as unstable. P1 and P2 according to microperimetry data represent the percentage of fixation points located within circles with diameters of 2 and 4 degrees.

All patients underwent minimally invasive vitrectomy using $25 \mathrm{G}$ or $27 \mathrm{G}$ techniques.

Statistical calculations were performed using STATISTICA 10 (StatSoft, USA) and Numbers (Apple Inc., USA) for quantitative attributes: BCVA, photosensitivity of the macular area $(\mathrm{dB})$, stability of fixation (\%), maximal macular hole diameter $(\mu \mathrm{m})$. According to the small access, the nonparametric Wilcoxon criterion was used to determine differences between the pre-op and post-op results. Differences were considered statistically significant at $\mathrm{p}<0.05$.

Exclusion criteria:

- Traumatic macular hole;

Citation: AS Balalin., et al. "Role of Microperimetry in Observation and Treatment in Patients with Macular Holes". Acta Scientific Ophthalmology 4.7 (2021): 44-48 


\section{Results}

The patients were divided into 4 groups according to the Gass classification in order to assess the treatment results. Lamellar macular hole was diagnosed in 15 patients (15 eyes), stage 2 fullthickness macular hole in 12 patients (12 eyes), stage 3 - in 15 patients (15 eyes), stage 4 - in 17 patients (17 eyes).

The average values of the pre-op results are presented in table 1. The table shows that as the IMH stage increases, there is a sig- nificant decrease in BCVA and retinal photosensitivity according to microperimetry data.

Retinal photosensitivity pre-op depended on the IMH size (Figure 1): the larger the maximal IMH diameter, the lower the patients' retinal photosensitivity was.

After minimally invasive vitrectomy, complete closure of the macular hole was achieved in all cases. There were no intra- and postoperative complications.

\begin{tabular}{|l|c|c|c|c|c|}
\hline \multirow{2}{*}{$\begin{array}{c}\text { Indicators } \\
\text { Groups }\end{array}$} & Number & BCVA pre-op & \multicolumn{2}{c|}{ Microperimetry pre-op } \\
\cline { 4 - 6 } & of eyes & & $\begin{array}{c}\text { Photosensitivity of } \\
\text { the macula, dB }\end{array}$ & P1, \% & P2, \% \\
\hline Lamellar macular hole & 15 & $0,36 \pm 0,08$ & $23 \pm 0,8$ & $78,8 \pm 11,5$ & $97,2 \pm 1,6$ \\
\hline $2^{\text {nd }}$ stage of IMH & 12 & $0,24 \pm 0,08$ & $21,6 \pm 1,2$ & $83 \pm 14$ & $94 \pm 6$ \\
\hline $3^{\text {rd }}$ stage of IMH & 15 & $0,18 \pm 0,08$ & $22,2 \pm 1$ & $71,9 \pm 6,1$ & $92,1 \pm 3,7$ \\
\hline $4^{\text {th }}$ stage of IMH & 17 & $0,14 \pm 0,06$ & $18,6 \pm 1$ & $59 \pm 12$ & $91 \pm 5,4$ \\
\hline
\end{tabular}

Table 1: Mean values of the visometry and microperimetry pre-op results, $M \pm \sigma$.

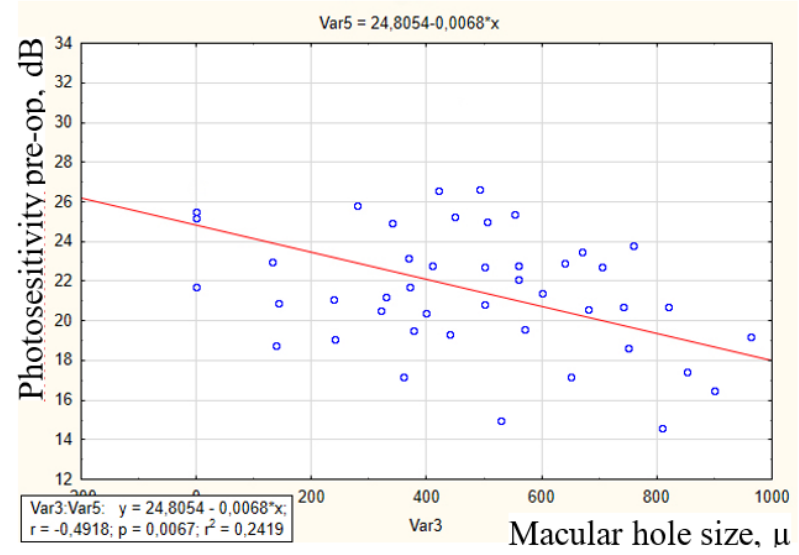

Figure 1: Dependence of retinal photosensitivity on the macular hole size pre-op.

Table 2 shows the mean BCVA and photosensitivity values after minimally invasive vitrectomy. After surgical treatment there was a significant improvement of BCVA and retinal photosensitivity.
In the $1^{\text {st }}$ group, patients significantly improved BCVA by 0.06 $(\mathrm{p}<0.01)$ and retinal photosensitivity by $1.2 \mathrm{~dB}(\mathrm{p}<0.05)$. P1 increased by $9 \%(p<0.01)$, P2 increased by $0.2 \%(p<0.05)$.

In the $2^{\text {nd }}$ group, patients' BCVA improved by $0.14(\mathrm{p}<0.01)$ and retinal photosensitivity by $0.06 \mathrm{~dB}(\mathrm{p}<0.05)$. P1 increased by $13.1 \%(\mathrm{p}<0.01)$, P2 increased by $5.5 \%(\mathrm{p}<0.05)$.

In the $3^{\text {rd }}$ group, the patients had significantly improved BCVA by $0.12(\mathrm{p}<0.01)$ and retinal photosensitivity by $0.09 \mathrm{~dB}(\mathrm{p}<0.05)$. P1 increased by $2.6 \%$ ( $<<0.01)$, P2 increased by $0.3 \%(p<0.05)$.

In the $4^{\text {th }}$ group, patients had a $0.14(\mathrm{p}<0.01)$ improvement in BCVA and a $2.8 \mathrm{~dB}$ improvement in retinal photosensitivity $(\mathrm{p}<$ 0.05). P1 increased by $13.2 \%(\mathrm{p}<0.01)$ and $\mathrm{P} 2$ increased by $1.6 \%$ $(\mathrm{p}<0.05)$.

Considering the improvement of BCVA in all clinical groups after minimally invasive vitrectomy, it was supposed, that was a possibility of post-op BCVA predicting basing on data of the pre-op retinal photosensitivity and maximal macular hole diameter. Figure 2 shows the dependence of postoperative BCVA on the pre-op microperimetry indicators and macular hole size. 


\begin{tabular}{|c|c|c|c|c|c|}
\hline \multirow{2}{*}{$\begin{array}{c}\text { Indicators } \\
\text { Groups }\end{array}$} & \multirow[b]{2}{*}{$\underset{\text { eyes }}{\text { Number of }}$} & \multirow[b]{2}{*}{ BCVA pre-op } & \multicolumn{3}{|c|}{ Microperimetry pre-op } \\
\hline & & & $\begin{array}{l}\text { Photosensitivity of } \\
\text { the macula, dB }\end{array}$ & $\mathbf{P 1}, \%$ & $\mathrm{P} 2, \%$ \\
\hline $\begin{array}{l}\text { Lamellar macular } \\
\text { hole }\end{array}$ & 15 & $0,42 \pm 0,09(+17 \%)$ & $24,2 \pm 1(+5 \%)$ & $86,2 \pm 5,1(+9 \%)$ & $97,4 \pm 1,6(+0,2 \%)$ \\
\hline $2^{\text {nd }}$ stage of IMH & 12 & $0,38 \pm 0,09(+58 \%)$ & $22,6 \pm 1,1(+5 \%)$ & $95,5 \pm 4,5(+13,1 \%)$ & $99,5 \pm 1(+5,5 \%)$ \\
\hline $3^{\text {rd }}$ stage of IMH & 15 & $0,3 \pm 0,09(+67 \%)$ & $22,9 \pm 0,9(+3 \%)$ & $73,8 \pm 7,1(+2,6 \%)$ & $92,4 \pm 2,3(+0,3 \%)$ \\
\hline $4^{\text {th }}$ stage of IMH & 17 & $\begin{array}{c}0,28 \pm 0,12 \\
(+100 \%)\end{array}$ & $21,4 \pm 1,4(+15 \%)$ & $68 \pm 11,8(+13,2 \%)$ & $92,5 \pm 4,7(+1,6 \%)$ \\
\hline
\end{tabular}

Table 2: Mean values of visometry and microperimetry post-op results, $M \pm \sigma$.

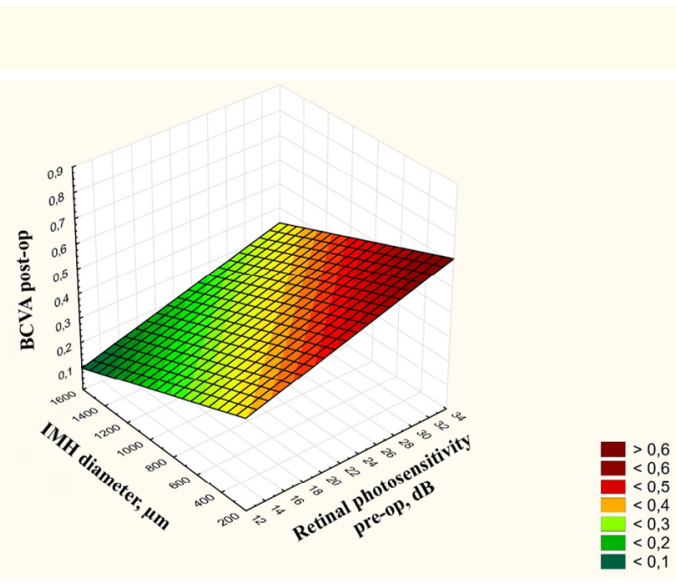

Figure 2: Dependence of post-op BCVA on the pre-op microperimetry values and macular hole size.

Based on a multifactor correlation analysis, the dependence of post-op BCVA on the pre-op photosensitivity and the maximal macular hole size was revealed, described with following formula:

$Z=0,2787+0,011 \times X-0,0002 \times Y$, where

$\mathrm{Z}$ - BCVA post-op, $\mathrm{X}$ - value of the retinal photosensitivity in the macular area pre-op $(\mathrm{dB}), \mathrm{Y}$ - maximal macular hole diameter preop $(\mu \mathrm{m})$.

The formula shows that higher pre-op retinal photosensitivity value and smaller the IMH diameter are associated with higher the post-op BCVA can be predicted. This formula may be used to predict the results of surgical treatment.
Further research on the prediction of IMH treatment results will be continued using data from optical coherence tomography with an angiography program.

\section{Conclusion}

Microperimetry is a modern noninvasive method of examination, which allows to localize central visual field defects with higher density and resolution, to carry out careful monitoring before and after surgical treatment.

The study of retinal photosensitivity in the macular area and the maximal macular hole size pre-op allows to predict BCVA in the postoperative period, which has a practical importance.

\section{Bibliography}

1. RN Johnson and JD Gass. "Idiopathic macular holes. Observation, stages of formation, and implications for surgical intervention". Ophthalmology 95.7 (1988): 917-924.

2. Shishkin MM., et al. "Comparative analysis of optical coherence tomography and microperimetry data for assessment of central retinal regions in recurrent macular hole RMJ". Clinical Ophthalmology 2 (2020): 51-55.

3. Ioileva E.E and Krivosheeva MS. "Microperimetry in optical neuritis due to multiple sclerosis". Ophthalmosurgery 3 (2016): 77-80.

4. Sabates NR. "The MP-1 microperimeter - clinical applications in retinal pathologies". Highlights of Ophthalmology 33.4 (2015): 1217. 
5. Lisochkina AB and Nechiporenko PA. "Microperimetry: advantages of the method and practical application". Ophthalmological Bulletin 2.1 (2019): 19-22.

6. Zotov AS., et al. "Choice of method of surgical treatment of macular hole". Modern Technologies in Ophthalmology 1 (2019): 62-65.

7. Dravitsa LV., et al. "Secondary glaucoma in eyes with silicone tamponade of vitreal cavity". VII Research and practice conference Modern techniques of vitreoretinal pathology treatment (2009): 67-68.

8. Velichko PB and Fabrikantov OL. "Results of surgical treatment of through macular holes of different diameters". Modern Technologies of Vitreoretinal Pathology Treatment (2011): 63-65.

9. Zhigulin AV., et al. "Surgical treatment of large diameter macular hole". New technologies of diagnostics and treatment of eye diseases in Far East region". (2012): 73-74.

10. Shkvorchenko DO., et al. "Surgical treatment of primary macular hole with platelet-rich blood plasma". Ophthalmosurgery 3 (2017): 27-30.

11. Shpak AA., et al. "Comparative efficacy of surgical treatment of macular ruptures with platelet-rich blood plasma". Ophthalmosurgery 3 (2018): 75-79.

12. Avetisov SE and Surguch VK. "Idiopathic macular hole". Atlases on Ophthalmology Retina (2009): 44.

13. Saidova RD. "To a question about silicone emulsification-induced secondary glaucoma". Proceedings of Daghestan State Pedagogical University. Natural and Exact Sciences (2013): 71-75.

14. Chuprov AD., et al. "Experience of surgical treatment of macular ruptures using platelet-enriched autoplasma (first clinical results)". Practical Medicine (2017): 247-249.

15. Zakharov VD., et al. "Efficacy of platelet-rich blood plasma in surgery of large macular holes". Practical Medicine (2016):

118-121.

\section{Volume 4 Issue 7 July 2021}

\section{(C) All rights are reserved by AS Balalin., et al.}

